\title{
DISTRIBUIÇÃO ESPACIAL DA EROSIVIDADE DAS CHUVAS NA BACIA DO RIO MANUEL ALVES DA NATIVIDADE, TOCANTINS
}

\author{
Rainfall Erosivity Spacial Distribuction in Manuel Alves da Natividade River \\ Basin, State of Tocantins, Brazil
}

Virgílio Loureço Silva Neto ${ }^{1}$ Elismar Dias Batista ${ }^{2}$

Wilmar Borges Leal Junior ${ }^{3}$ Zanine Vargas Fabris 4 Pedro James Almeida Wolney Rodrigues ${ }^{5}$

Palavras-chave:

Hidrologia.

Interpolação.

Perda de solo.

Precipitação.

\begin{abstract}
Resumo
O objetivo deste trabalho foi calcular os valores de erosividade e realizar o mapeamento da erosividade mensal e anual das chuvas na Bacia do Rio Manuel Alves da Natividade, região sudeste do estado do Tocantins, com base no interpolador Krigagem ordinária (KO), a partir da avaliação de desempenho dos modelos esférico, exponencial e gaussiano, a partir de dados de precipitação referente ao período de 1983 a 2013. A geoestatística foi aplicada para o mapeamento da erosividade tanto na escala mensal quanto na anual. A erosividade anual apresentou valores entre 8.332 e $9.253 \mathrm{MJ} \mathrm{mm} \mathrm{ha}^{-1} \mathrm{~h}^{-1} \mathrm{ano}^{-1}$, com auge em dezembro, quando atingiu valores de até $2.170 \mathrm{MJ} \mathrm{mm}$ $\mathrm{ha}^{-1} \mathrm{~h}^{-1}$ ano $^{-1}$ por mês. De maio a setembro, a erosividade apresentou valores inferiores ao crítico, tido como $500 \mathrm{MJ} \mathrm{mm} \mathrm{ha}^{-1} \mathrm{~h}^{-1} \mathrm{ano}^{-1}$ por mês. Foram identificadas três regiões críticas para ações de planejamento visando a conservação do solo e da água: noroeste, norte e central da bacia do rio Manuel Alves da Natividade.
\end{abstract}

\footnotetext{
Instituto Federal de Educação, Ciência e Tecnologia do Tocantins, Campus Gurupi, Tocantins. virgilio.neto@ifto.edu.br

2 Instituto Federal de Educação, Ciência e Tecnologia do Tocantins, Campus Dianópolis, Tocantins. elismar.batista@ifto.edu.br

3 Instituto Federal de Educação, Ciência e Tecnologia do Tocantins, Campus Dianópolis, Tocantins. wilmar.junior@ifto.edu.br

${ }^{4}$ Instituto Federal de Educação, Ciência e Tecnologia do Tocantins, Campus Paraíso do Tocantins, Tocantins. zanine.fabris@ifto.edu.br

5 Instituto Federal de Educação, Ciência e Tecnologia do Tocantins, Campus Dianópolis, Tocantins. pjdno@hotmail.com
} 
Keywords:

Erosivity.

Soil loss.

Hydrology.

Interpolation.

Precipitation.

\begin{abstract}
We calculated Manuel Alves da Natividade river basin erosivity, Tocantins state southwest region, using Ordinary kriging interpolator method. All spherical, exponential and Gaussian models were tested. We analyzed Rainfall dates from 1983 to 2013. To map mensal and annual erosivity, we applied geostatistical techniques. Annual erosivity showed values between 8332 and $9253 \mathrm{MJ} \mathrm{mm}$ ha${ }^{1} \mathrm{~h}^{-1}$ year $^{-1}$. December presented strongest erosivity numbers, until $2170 \mathrm{MJ} \mathrm{mm} \mathrm{ha}^{-1} \mathrm{~h}^{-1}$ month $^{-1}$. No critical erosivity values were found between May and September Northwest, North and Central are critical regions with highest erosivity numbers and demand special attention about soil preservation.
\end{abstract}

\section{INTRODUÇÃO}

$\mathrm{O}$ índice de erosividade (EI) expressa o potencial erosivo das chuvas (WISCHMEIER, 1958). Segundo Hickmann et al. (2008), a capacidade potencial das chuvas em provocar erosão pode ser definida como erosividade expressa por meio deste índice. Ainda segundo estes autores, danos irreversíveis ao solo e redução nos rendimentos das culturas ocorrem por causa da erosão, sendo por isso, necessários programas de controle da erosão hídrica para que a agricultura estável possa ser praticada.

Segundo Viola et al. (2014), o conhecimento da erosividade, tanto no espaço quanto no tempo, é fundamental para o planejamento de práticas de manejo e de conservação do solo e da água que visam minimizar os efeitos adversos da erosão hídrica. Neste sentido, a determinação dos valores da erosividade, ao longo do ano, permite identificar os meses nos quais os riscos de perdas de solo são mais elevados, razão por que exerce papel relevante no planejamento de práticas conservacionistas fundamentadas na máxima cobertura do solo nas épocas críticas de maior capacidade erosiva das chuvas.
(WISCHMEIER; SMITH， 1978; BERTONI; LOMBARDI NETO, 1993).

A expansão da fronteira agrícola no estado Tocantins reflete a crescente demanda por commodities agrícolas e, com o contínuo desenvolvimento das técnicas de produção, o estado vem aumentando sua área agricultável. Assim, no que se refere ao manejo e conservação do solo, deve-se considerar o tipo de cultura empregado, mas é de grande importância a compreensão da estrutura do solo para a eficiência produtiva, que passa pela interpretação de dados relacionados com a intensidade e a frequência das chuvas (SILVA NETO et al., 2015).

Silva (2004) afirma que os mapas de erosão podem ser úteis para os ambientalistas e os agrônomos para obter conhecimento sobre o potencial de erosividade da precipitação em determinados locais, a fim de implementar as precauções necessárias para minimizar a erosão do solo nessas áreas.

Estudos sobre a erosividade das chuvas foram desenvolvidos por Viola et al. (2014) para o estado do Tocantins, Silva Neto (2015) para a cidade de Taguatinga na região sudeste deste estado. Considerando o âmbito nacional, 
Oliveira et al. (2015) realizou estudos com o objetivo de espacializar a erosividade das chuvas no Brasil a partir de séries sintéticas de precipitação, cujo trabalho foi realizado para o território nacional usando dados de 142 estações pluviográficas. Para diversas regiões do país, o potencial erosivo das chuvas foi amplamente estudado, Morais et al. (1991), para o sudoeste de Mato Grosso, Lombardi Neto e Moldenhauer (1992) para a cidade de Campinas-SP, Silva et al. (1997), para a região de Goiânia, Mello et al. (2007) e Silva et al. (2010), para o estado de Minas Gerais, Cassol et al. (2008), para São Borja, no Rio Grande do Sul.

No âmbito internacional, a erosividade das chuvas é importante objeto de estudo. Haas et al. (2018), em estudos realizados para modelar condições climáticas e índices de erosividade ao norte da Floresta Negra, Alemanha, afirmam que que ecossistemas florestais estáveis não sejam propensos à perda de solo. Além disso, a erosividade das chuvas é baixa e práticas que promovam a erosão, como cortes, são raras. No entanto, numa perspectiva de mudanças climáticas, os autores afirmam que espera-se um aumento nos fenômenos climáticos extremos. Por exemplo, no sudoeste da Alemanha, a ocorrência de fortes tempestades durante o inverno.

Vrieling et al. (2010) afirmam que na África, a erosão do solo induzida pelo homem resulta de uma pressão crescente nos recursos naturais, levando a um uso mais intensivo do solo (por exemplo, através de alterações do uso da terra), realidade que se assemelha ao que ocorre no cerrado brasileiro a partir da expansão da fronteira agrícola.

Considerando a importância da erosividade das chuvas na perda de solos, particularmente em regiões muito degradadas e com chuvas erosivas concentradas, o objetivo deste trabalho foi calcular os valores de erosividade e realizar o mapeamento da erosividade mensal e anual das chuvas na Bacia do Rio Manuel Alves da Natividade, região sudeste do estado do Tocantins, com base no interpolador Krigagem ordinária (KO), a partir da avaliação de desempenho dos modelos esférico, exponencial e gaussiano, a partir de dados de precipitação referente ao período de 1983 a 2013.

\section{MATERIAL E MÉTODOS}

A bacia do Rio Manuel Alves da Natividade pertence ao sistema hidrográfico do rio Tocantins (margem direita), com uma área de drenagem de 14.934,93 $\mathrm{km}^{2}$, contemplando 11 municípios, que abrangem uma área de aproximadamente $22.576 \mathrm{~km}^{2}$ (Figura 1). É, é de grande importância para o Estado do Tocantins, pois nela se localiza o Projeto Manuel Alves, região sudeste, um dos grandes projetos de irrigação do país, pela dimensão de seu reservatório de águas e pela extensão da área irrigável, por microaspersão, gotejamento e aspersão convencional, onde se pratica a cultura de abacaxi, banana, coco, mamão, maracujá e melancia, além de mandioca, milho, tomate, abóbora cabutiá, cana-de-açúcar, goiaba e pupunha (SEPLAN, 2012). 
Figura 1. Localização da bacia do rio Manuel Alves da Natividade (A) e distribuição das estações utilizadas para mapeamento da erosividade das chuvas em modelo digital de elevação ASTER (B)

A

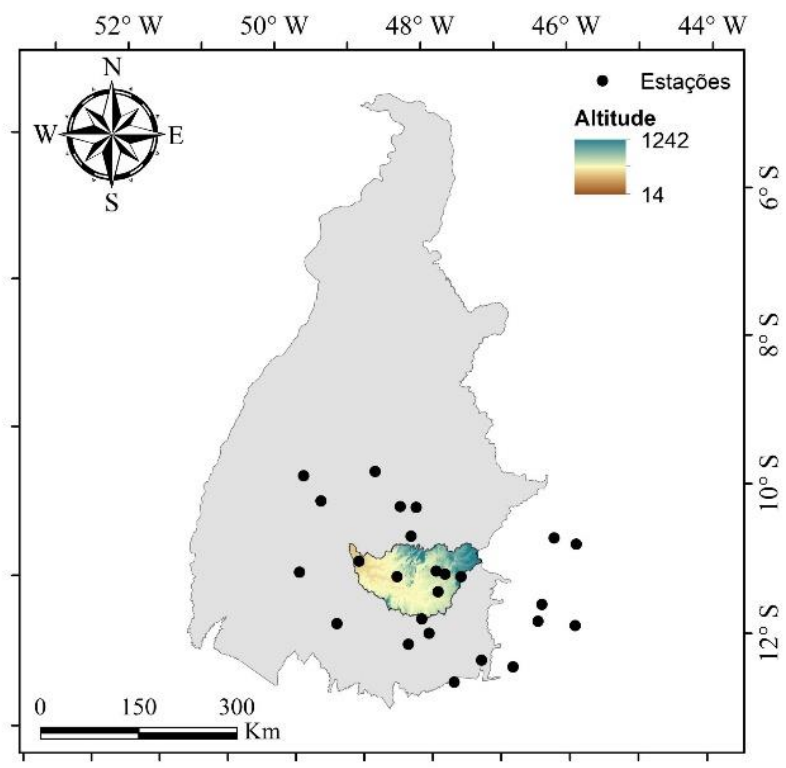

B

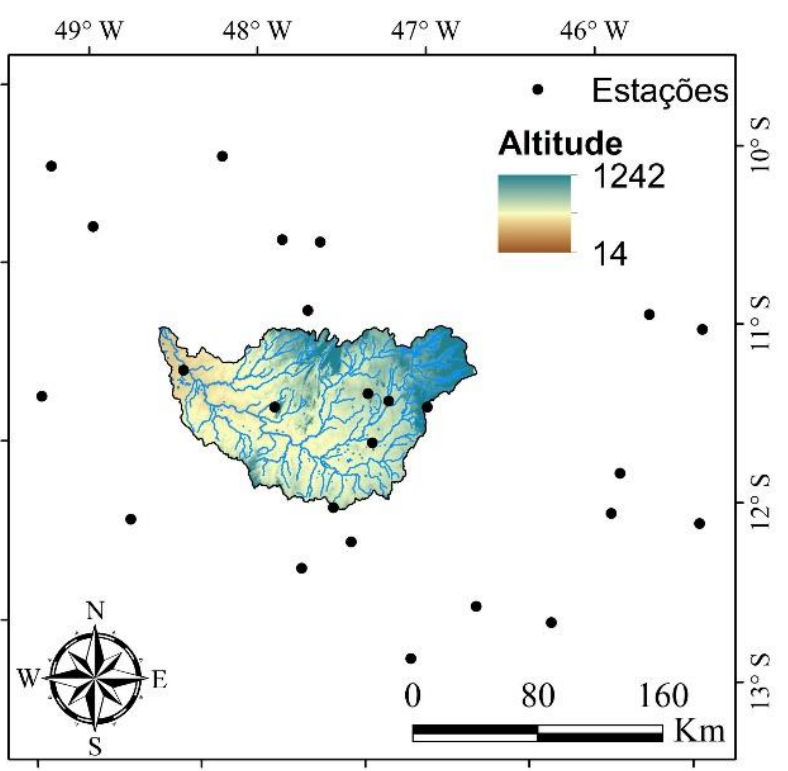

Fonte: Adaptado INPE, 2016. Org.: Autor, 2018.

Segundo Souza (2019), ocorrem no Estado do Tocantins três regiões climáticas homogêneas (Figura 2), sendo: a) região climática C1s2A'a': Clima subúmido seco, com grande concentração de chuvas no verão, megatérmico; b) região climática C2wA'a': clima subúmido, com deficiência de água moderada no inverno, megatérmico e c) região climática B1wA'a': clima úmido, com deficiência d'água moderada no inverno, megatérmico. A área da bacia do Rio Manuel Alves compreende a região climática $\mathrm{C} 2 \mathrm{wA}$ 'a'.

Neste estudo, foram utilizados dados obtidos do Sistema de Informações Hidrológicas (HidroWEB) da Agência Nacional de Águas (ANA). Vinte e cinco (25) estações pluviométricas foram selecionadas na área da bacia e seus arredores, obtendo-se séries históricas com monitoramento no período médio de 30 anos, entre 1983 e 2013.
Figura 2. Classificação climática de Thornthwaite e Matter para o Estado do Tocantins.

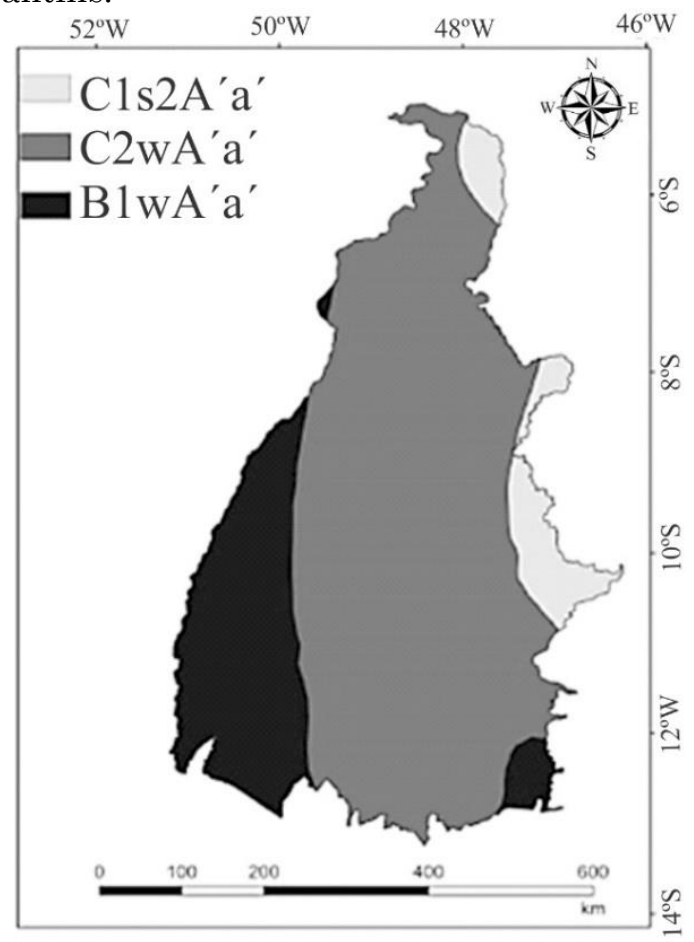

Fonte: Souza et al. (2019). Org.: Autor, 2018.

Para calcular a erosividade da chuva para um local, é recomendável que seja estimado o 
valor médio do índice de erosão para um período de, no mínimo, 20 anos (HICKMANN et al., 2008). A equação de Wischmeier e Smith (1958), que é considerada uma referência para estes estudos, tende a subestimar a erosividade da chuva em regiões tropicais.

A erosividade das chuvas, denominada fator "R" ou índice de erosividade EI30, representa numericamente a força erosiva, em $\mathrm{MJ} \mathrm{mm} \mathrm{ha}^{-1} \mathrm{~h}^{-1} \mathrm{ano}^{-1}$ como unidade de medida, sendo obtida pelo produto da energia cinética (Ec) com que uma chuva atinge o solo, pela máxima intensidade verificada em 30 minutos, conforme Equação 1.

$E i_{30}=E c . I_{30 \mathrm{~min}}$

A variável explicativa para o cálculo do índice $E I_{30}$ foi o índice de Fournier (Rc). Na determinação da erosividade das chuvas, utilizou-se a Equação 2, determinada por Silva et al. (1997), definida por:

$E i_{30}=216,15+30,762 \times R c$

Onde, (EI30) é a erosividade da chuva para cada mês (MJ mm ha-1 $\mathrm{h}^{-1} \mathrm{ano}^{-1}$ ) e Rc o Índice de Fournier, determinado pela equação 3:

$R c=\left(\frac{\mathrm{M}_{\mathrm{X}}^{2}}{\mathrm{P}}\right)$

Em que $M_{x}$ é a média do total mensal de precipitação, em mm e $\mathrm{P}$ é a média do total anual de precipitação, em $\mathrm{mm}$, sendo desta forma, determinado o índice de Fournier. Esta equação foi utilizada devido ao padrão de chuvas predominante na região da bacia do rio Manuel Alves da Natividade, validada por estudos realizados por Viola et al. (2014), por meio do Índice de Concentração de Precipitação (ICP), semelhante ao regime pluviométrico da área em questão.

O índice de erosividade anual das chuvas (R) é o somatório dos valores mensais desse índice, conforme Equação 4 abaixo:

$R=\sum_{1}^{12} E i_{30}$

Para o mapeamento da erosividade foram testados os interpoladores Krigagem ordinária (KO), inverso da potência da distância (IPD), considerando as potências de 2 a 5 , sendo utilizado o interpolador com melhor desempenho.

Para a análise geoestatística, uma etapa essencial consiste no ajuste do modelo de semivariograma teórico, obtendo-se valores para os parâmetros que estruturam tais modelos (efeito pepita, contribuição e alcance). Neste estudo, foram avaliados os modelos de semivariograma esférico, exponencial e gaussiano, tendo sido aplicado o método de ajuste dos Mínimos Quadrados Ponderados (MQP). Nas Equações $5, \quad 6 \quad$ e 7 estão apresentados os modelos de semivariograma esférico, exponencial e gaussiano, respectivamente.

$$
\begin{aligned}
& \gamma(h)=C_{0}+C_{1} \cdot\left[\frac{3}{2} \cdot\left(\frac{h}{a}\right)-\frac{1}{2} \cdot\left(\frac{h}{a}\right)^{3}\right], \text { se } 0<h<a \\
& \gamma(h)=C O+C 1 ; h \geq a
\end{aligned}
$$


$\gamma(h)=C_{0}+C_{1} \cdot\left[1-\exp \left(\frac{-3 \cdot h}{a}\right)\right]$, se $0<h<a ; \gamma(h)$

$=C O+C 1 ; h>a$

$\gamma(h)=C_{0}+C_{1} \cdot\left\{1-\exp \left[-3 \cdot\left(\frac{h}{a}\right)^{2}\right]\right\}$, se $0<h<a$

$\gamma(h)=C O+C l ; h>a$

Sendo, $\gamma(h)$ a semivariância, $\mathrm{C}_{1} \quad \mathrm{a}$ contribuição do semivariograma (diferença entre o patamar e o efeito pepita), a o alcance, $\mathrm{C}_{0}$ o efeito pepita e $h$ a distância entre os pares de pontos.

Com o intuito de analisar a estrutura de dependência espacial dos modelos de semivariograma ajustados foi calculado o grau de dependência espacial (GD), sendo obtido conforme Cambardella et al. (1994) por:

$G D=\left(\frac{C_{1}}{C_{0}+C_{1}}\right) \cdot 100$

Considerando o GD, pode-se adotar a seguinte classificação: GD < 25\% (fraco), entre 25 e 75\% (moderado) e > $75 \%$ (forte) (CAMBARDELLA et al., 1994).

A fim de verificar a qualidade da espacialização da erosividade, aplicou-se a técnica da validação cruzada. Esta técnica consiste em estimar os valores da variável em estudo para a exata localização dos pontos amostrados, permitindo quantificar o erro médio percentual absoluto (EMPA), em \%, conforme a Equação 9 (LEWIS, 1997):

$E M P A=\frac{1}{n} \cdot \sum_{i=1}^{n}\left|\frac{O b s_{i}-E s t_{i}}{O b s_{i}}\right| \cdot 100$

Em que, $n$ é o número de postos pluviométricos cujos dados foram utilizados na determinação do Fator (R), $O b s_{i}$ é a erosividade observada para o posto i e $E_{s} t_{i}$ é a erosividade estimada para a posição do posto i.

No presente trabalho adotou-se a classificação proposta por Lewis (1997), a qual apresenta os seguintes intervalos de valores: Empa $<10 \%$ : "muito bom"; 10\% $\leq$ Empa $<20 \%$ :

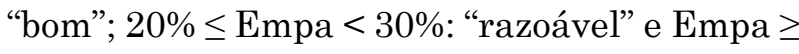
30\%: "impreciso".

O viés estatístico ou BIAS foi calculado de acordo com Liew et al. (2007), pela Equação 10. O valor do BIAS corresponde ao percentual de viés das variáveis estimadas com relação às variáveis observadas.

$B I A S=\frac{\sum_{i=1}^{n}\left(\text { obs }_{i}-E s t_{i}\right)}{\sum_{i=1}^{n}\left(O b s_{i}\right)} \cdot 100$

Os mapas encontram-se na Projeção Cônica de Albers, Datum SIRGAS 2000. A erosividade da chuva (EI30), em $\mathrm{MJ}^{\mathrm{mm}} \mathrm{ha}^{-1} \mathrm{~h}-$ 1 ano $^{-1}$, foi mapeada em escala de cor laranja, sendo que as classes de menores valores receberam coloração clara, seguindo para a coloração escura com seu incremento.

\section{RESULTADOS E DISCUSSÃO}

É possível identificar dois períodos distintos na distribuição de chuvas sobre a bacia do Rio Manuel Alves da Natividade. O período chuvoso se concentra nos meses de outubro a abril, enquanto o período seco ocorre entre maio a setembro, quando a precipitação média mensal não ultrapassou os $50 \mathrm{~mm}$. Analisando o regime de chuvas no Tocantins como um todo, Viola et al. (2014) também identifica estes dois períodos. No primeiro, as chuvas são mais bem 
distribuídas ao longo do ano, em uma extensa faixa desde o norte da Ilha do Bananal (sudoeste do Estado) até o sul da região do Bico do Papagaio; e, no segundo, as chuvas encontram-se mais concentradas, cobrindo todo o sul e o extremo norte do Estado.

Reboita et al. (2010) e Viola et al. (2014), afirmam que esta diferença na sazonalidade das chuvas é uma característica marcante da região central do Brasil, na qual, durante o período de estiagem, ocorre a intensificação do fenômeno anticiclone do Atlântico Sul, com redução da presença de vapor d'água na atmosfera, o que impede a organização de nuvens de chuva e o deslocamento de sistemas frontais.

Os meses com maiores índices de precipitação para a bacia são os mesmos para o Estado como um todo, entre dezembro e março, cuja lâmina acumulada atingiu mais de 1005 mm (Figura 3). Neste período, o potencial erosivo das chuvas alcançou $68,4 \%$ do total anual, indicando que nesses quatro meses, concentra-se o período crítico de impacto erosivo das chuvas (VIOLA et al., 2014).

Figura 3. Médias mensais de precipitação e erosividade entre 1983 e 2013, para os 25 postos utilizados no processo de modelagem, na bacia do Rio Manuel Alves da Natividade. A linha com intervalos pontilhados representa a faixa de variação da erosividade.

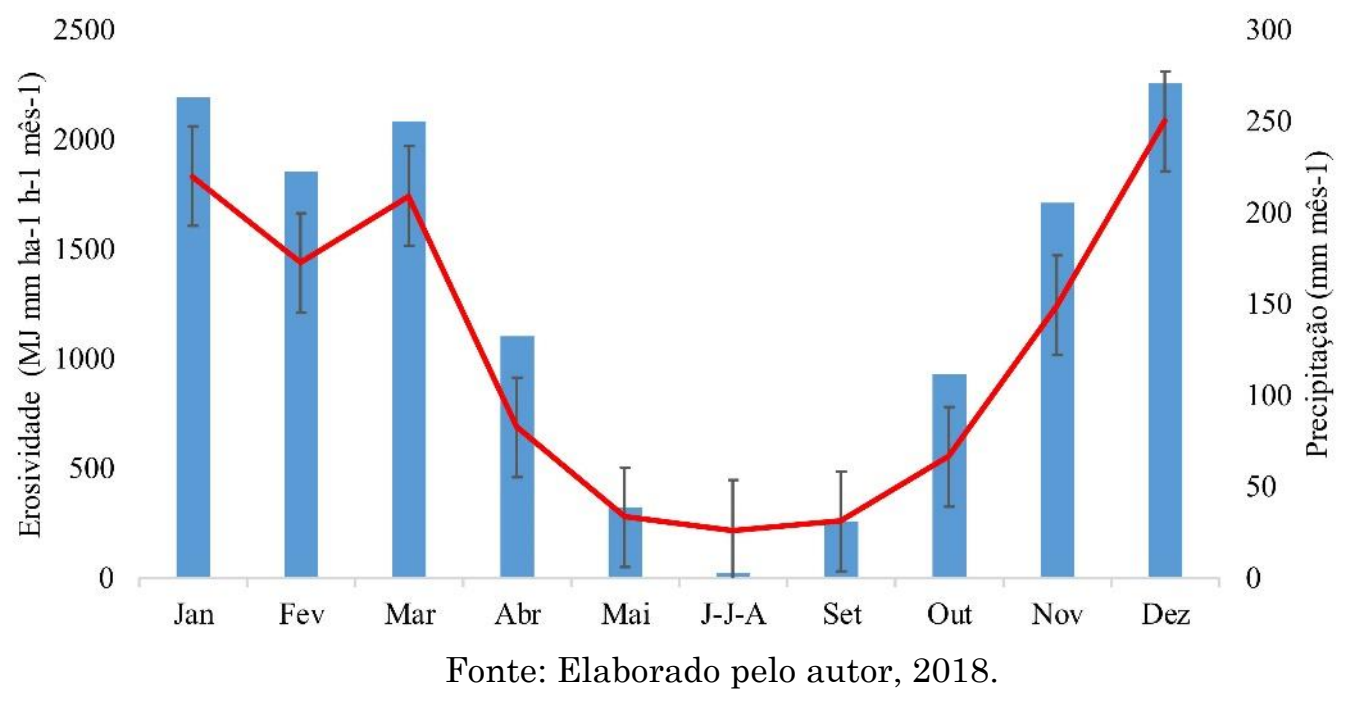

É importante destacar que em todo o período chuvoso, a erosividade esteve acima de $500 \mathrm{MJ} \mathrm{mm} \mathrm{ha}^{-1} \mathrm{~h}^{-1}$ mês $^{-1}$, e uma média de erosividade para o período chuvoso (outubro a março) de 1.481 MJ mm ha-1 $\mathrm{h}^{-1}$ mês $^{-1}$, considerados valores elevados que indicam perda de solo acima do tolerado, atribuindo a este período uma criticidade no que diz respeito a erosão, demandando a manutenção do solo com cobertura vegetal para reduzir as ações erosivas da chuva e, consequentemente, as elevadas perdas de solo (SILVA et al., 1997; VIOLA et al. 2014).

Considerando apenas os quatro meses mais chuvosos na região da bacia do Rio Manuel Alves da Natividade, a erosividade 
registrada corresponde a cerca de 7.095,07 $\mathrm{MJ}$ $\mathrm{mm} \mathrm{ha-1} \mathrm{h-1} \mathrm{ano}{ }^{-1}$. O total acumulado no restante do ano corresponde a 3.238,53 $\mathrm{MJ} \mathrm{mm}$ $\mathrm{ha}^{-1} \mathrm{~h}^{-1}$ ano $^{-1}, 46,2 \%$ da erosividade anual.

A erosividade anual determinada na bacia variou entre 8.332 e $14.403 \mathrm{MJ} \mathrm{mm} \mathrm{ha}^{-1}$ $\mathrm{h}^{-1} \mathrm{ano}^{-1}$. Os valores apresentam pequena variação com os encontrados por Viola et al. (2014), considerando a erosividade para todo o estado do Tocantins, entre 6,599 e $14.000 \mathrm{MJ}$ $\mathrm{mm} \mathrm{ha}^{-1} \mathrm{~h}^{-1} \mathrm{ano}^{-1}$. No âmbito do território brasileiro, Oliveira et al. (2015) encontrou valores de erosividade anual das chuvas variando entre 2.000 a $20.000 \mathrm{MJ} \mathrm{mm} \mathrm{ha}^{-1} \mathrm{~h}^{-1}$ ano $^{-1}$.

A Tabela 2 revela que $96 \%$ dos dados observados nas 25 estações apresentam erosividade anual classificada como "muito forte" e os restantes $4 \%$ classificados como "forte", revelando a necessidade de utilização de técnicas de manejo e conservação do solo adequadas para evitar a perda de solo por ação da erosividade das chuvas.

Tabela 2. Classe de interpretação da erosividade anual Fator (R).

\begin{tabular}{|c|c|c|}
\hline $\begin{array}{l}\text { Erosividade das } \\
\text { Chuvas } \\
\left(\mathrm{MJ} \mathrm{mm} \mathrm{ha}^{-1} \mathrm{~h}^{-1}\right. \\
\left.\text { ano }^{-1}\right)\end{array}$ & $\begin{array}{c}\text { Nível de } \\
\text { Erosividade }\end{array}$ & $\begin{array}{c}\text { Dados } \\
\text { observados } \\
(\%)\end{array}$ \\
\hline $\mathrm{R} \leq \mathbf{2 4 5 2}$ & Erosividade Fraca & $\mathbf{0}$ \\
\hline $2452<\mathrm{R} \leq 4905$ & Erosividade Média & $\mathbf{0}$ \\
\hline $4905<R \leq 7357$ & $\begin{array}{l}\text { Erosividade } \\
\text { Média-Forte }\end{array}$ & $\mathbf{0}$ \\
\hline $7357<\mathrm{R} \leq \mathbf{9 8 1 0}$ & Erosividade Forte & 44 \\
\hline $\mathrm{R}>\mathbf{9 8 1 0}$ & $\begin{array}{c}\text { Erosividade Muito } \\
\text { Forte }\end{array}$ & 56 \\
\hline
\end{tabular}

Fonte: Carvalho (2008), modificado para o S.I. métrico de unidades segundo Foster et al. (1981). Org.: Adaptado pelo autor, 2018.
Para a espacialização dos dados de erosividade da chuva (Fator R), o modelo esférico apresentou melhor desempenho em $20 \%$ em 10 análises, o modelo exponencial em $40 \%$, mesma porcentagem do modelo gaussiano, que apresentou também melhor desempenho em $40 \%$ das situações analisadas (Tabela 3). Destaca-se que para os meses de junho, julho e agosto foi obtida média de precipitação, considerando a escassez de chuva neste período, média utilizada para a análise geoestatística e para a espacialização da erosividade das chuvas.

A Tabela 3 apresenta o desempenho e os parâmetros dos modelos de semivariograma esférico, exponencial e gaussiano obtidos por meio da Krigagem ordinária. Nota-se que o Empa foi menor que 20\% para todos os meses com a exceção de março e abril, quando apresentou valores máximos. Para o período de Junho, Julho e Agosto, analisado a partir da média para o período, os valores baixos do EMPA se justificam pelos parâmetros de ajuste da equação utilizada, que produziu resultados com baixa variabilidade para o período.

Considerando a erosividade anual, o modelo exponencial apresentou melhor desempenho que o modelo esférico e gaussiano, com base no EMPA, além disso, destaca-se no modelo exponencial $100 \%$ de dependência espacial. Em ambos os modelos testados de semivariogramas, de acordo com Cambardella et al., (1994), constata-se "forte" dependência espacial (acima de 75\%) (Tabela 4). 
Tabela 3. Efeito pepita (C0), alcance (A), Contribuição (C1), Erro médio percentual absoluto (EMPA) e grau de dependência espacial (GD) para os modelos de semivariograma exponencial e esférico.

\begin{tabular}{|c|c|c|c|c|c|c|c|c|c|c|}
\hline Parâmetro & 1 & 2 & 3 & 4 & 5 & 6 & 7 & 8 & 9 & 10 \\
\hline \multicolumn{11}{|c|}{ Modelo Esférico } \\
\hline $\mathrm{C} 0$ & 44964,14 & 21931,74 & 0,00 & 0,00 & 0,00 & 0,00 & 2,84 & 1004,53 & 3181,65 & 216,24 \\
\hline $\mathrm{A}(\mathrm{Km})$ & 242,19 & 221,23 & 261,79 & 128,80 & 124,72 & 106,96 & 99,79 & 210,19 & 186,07 & 98,89 \\
\hline $\mathrm{C} 1$ & 86248,08 & 106163,94 & 436273,30 & 39184,98 & 886,92 & 11,35 & 157,48 & 6272,18 & 1851,61 & 4922,34 \\
\hline EMPA (\%) & 15,23 & 17,42 & 24,03 & 21,07 & 5,83 & 0,71 & 3,65 & 7,91 & 5,09 & 2,90 \\
\hline GD (\%) & 65,73 & 82,88 & 100,00 & 100,00 & 100,00 & 100,00 & 98,23 & 86,20 & 36,79 & 95,79 \\
\hline \multicolumn{11}{|c|}{ Modelo Exponencial } \\
\hline $\mathrm{C} 0$ & 28529,14 & 7927,03 & 0,00 & 0,00 & 0,00 & 0,00 & 0,00 & 575,33 & 1002,45 & 0,00 \\
\hline $\mathrm{A}(\mathrm{Km})$ & 292,53 & 268,39 & 444,84 & 39,18 & 247,14 & 169,25 & 137,04 & 349,92 & 95,15 & 130,56 \\
\hline $\mathrm{C} 1$ & 109408,59 & 127410,38 & 505792,85 & 40329,76 & 1054,57 & 12,72 & 172,47 & 7900,72 & 3866,29 & 5480,33 \\
\hline EMPA (\%) & 15,04 & 16,97 & 23,11 & 22,98 & 5,77 & 0,75 & 3,63 & 7,99 & 4,70 & 2,90 \\
\hline GD (\%) & 79,32 & 94,14 & 100,00 & 100,00 & 100,00 & 100,00 & 100,00 & 93,21 & 79,41 & 100,00 \\
\hline \multicolumn{11}{|c|}{ Modelo Gaussiano } \\
\hline $\mathrm{C} 0$ & 46239,63 & 35385,42 & 21974,91 & 765,98 & 117,38 & 0,19 & 41,38 & 1968,11 & 3621,79 & 1524,07 \\
\hline $\mathrm{A}(\mathrm{Km})$ & 158,34 & 189,54 & 214,59 & 110,52 & 113,23 & 95,15 & 99,79 & 192,44 & 186,07 & 95,15 \\
\hline $\mathrm{C} 1$ & 79775,42 & 94344,12 & 430076,98 & 41138,63 & 791,88 & 11,82 & 123,85 & 5490,89 & 1521,55 & 3676,33 \\
\hline EMPA (\%) & 14,63 & 17,64 & 25,45 & 21,95 & 5,69 & 0,72 & 3,68 & 7,41 & 2,95 & 2,95 \\
\hline GD (\%) & 63,31 & 72,72 & 95,14 & 98,17 & 87,09 & 98,43 & 74,96 & 73,61 & 29,58 & 70,69 \\
\hline
\end{tabular}

(1) Janeiro, (2) Fevereiro, (3) Março, (4) Abril, (5) Maio, (6) Junho/Julho/Agosto, (7) Setembro, (8) Outubro,

(9) Novembro e (10) Dezembro. Fonte: Elaborado pelo autor, 2018.

Tabela 4. Parâmetros dos modelos de semivariograma exponencial, esférico e gaussiano (efeito pepita (C0), contribuição (C1), alcance (A)), grau de dependência espacial (GD), Bias e erro médio percentual absoluto (EMPA) obtido por validação cruzada para a erosividade anual das chuvas na Bacia do Rio Manuel Alves da Natividade.

\begin{tabular}{ccccccc}
\hline & E. Pepita - C0 & Alcance (Km) & Contribuição - C1 & BIAS (\%) & EMPA (\%) & GD (\%) \\
\hline Esférico & 0,00 & 255,54 & 2471316,02 & 0,89 & 8,42 & 100,00 \\
Exponencial & 0,00 & 453,34 & 2937989,24 & 0,96 & 8,26 & 100,00 \\
Gaussiano & 155023,93 & 194,21 & 2294880,31 & 0,96 & 8,64 & 93,67
\end{tabular}

Fonte: Elaborado pelo autor, 2018.

As Figuras 4 e 5 apresentam os modelos de semivariograma com menor Empa para as análises mensais e anuais, respectivamente. Observa-se aderência moderada entre os modelos de semivariogramas experimentais, com forte dependência espacial para a maioria das análises, excluindo-se os meses de janeiro, outubro e novembro, com GD equivalente a $63 \%, 73,3 \%$ e $29,6 \%$, respectivamente, que apresentam dependência espacial moderada (CAMBARDELLA et al., 1994).

O alcance da estrutura de dependência espacial variou entre 106 (junho, julho e agosto) e $440 \mathrm{~km}$ (março), o que indica que as técnicas geoestatísticas podem produzir bons resultados no mapeamento da erosividade na bacia do rio Manuel Alves da Natividade. 
Figura 4. Semivariogramas ajustados para o potencial erosivo das chuvas na bacia do rio Manuel Alves da Natividade, modelo Esférico (A), Exponencial (B) e Gaussiano (C).
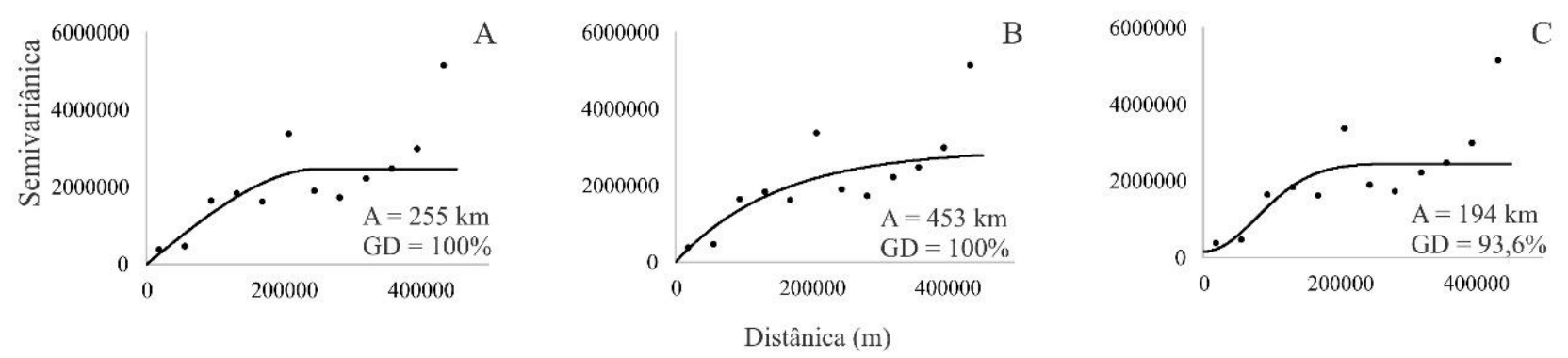

Fonte: Elaborado pelo autor, 2018.

Figura 5. Semivariogramas ajustados para o potencial erosivo das chuvas, na bacia do rio Manuel Alves da Natividade para os meses de Janeiro (A), Fevereiro (B), Marco (C), Abril (D), Maio (E), JunhoJulho-Agosto (F), Setembro (G), Outubro (H) Novembro (I) e Dezembro (J), com destaque para o alcance (A) e grau de dependência espacial (GD).
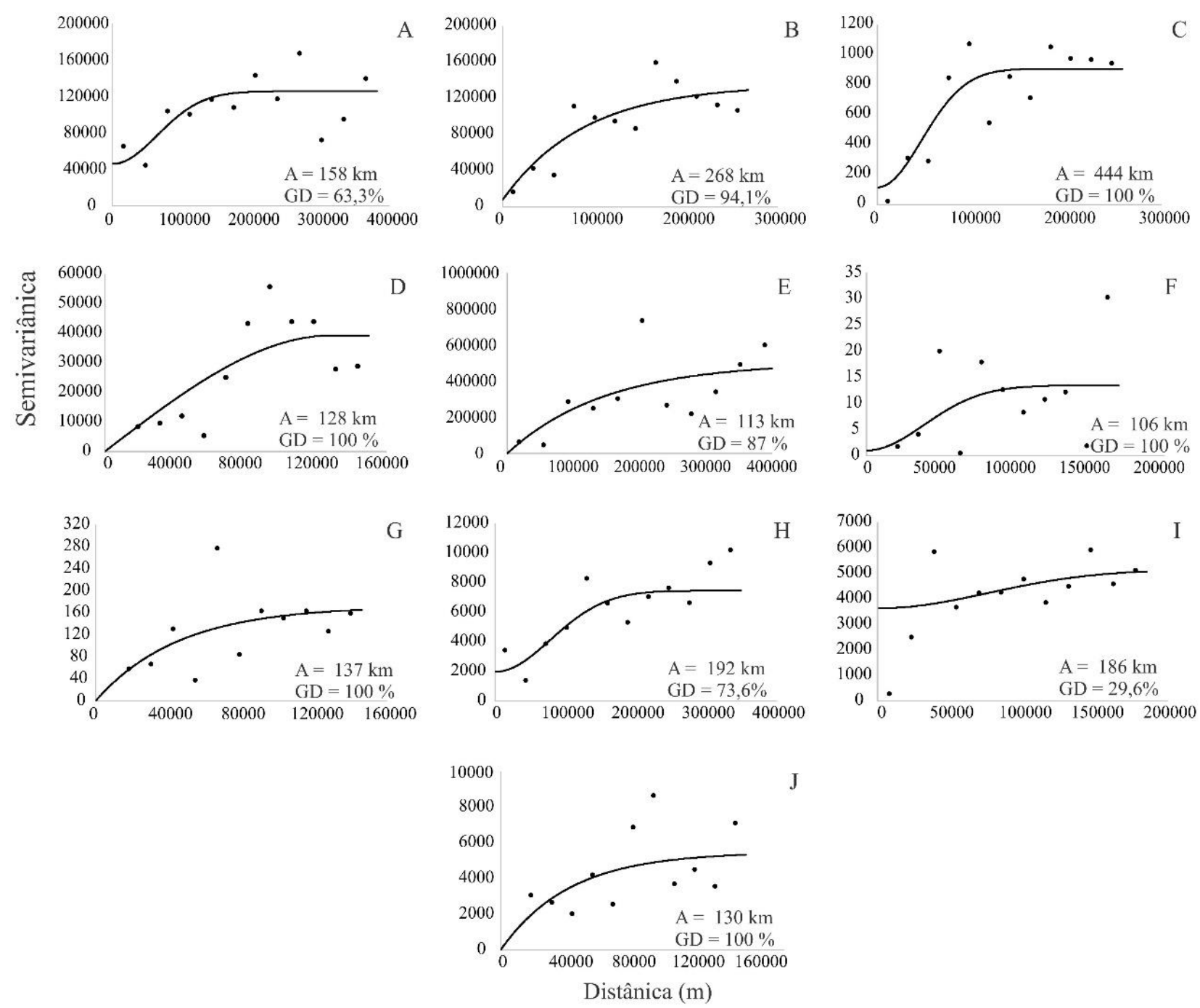

Fonte: Elaborado pelo autor, 2018. 
$\mathrm{Na}$ espacialização dos dados de erosividade das chuvas na bacia do rio Manuel Alves da Natividade, os maiores valores encontrados para os três primeiros meses do ano concentram-se na porção oeste, nordeste e noroeste da bacia, respectivamente. Em janeiro, variando entre 1.283 e $2.384 \mathrm{MJ} \mathrm{mm}$ $\mathrm{ha}^{-1} \mathrm{~h}^{-1}$ mês $^{-1}$. Em fevereiro, a variação foi entre 1.184 e $2.373 \mathrm{MJ} \mathrm{mm} \mathrm{ha}^{-1} \mathrm{~h}^{-1}$ mês $^{-1}$, em março, os valores variaram entre 973 e $3.936 \mathrm{MJ} \mathrm{mm}$ $\mathrm{ha}^{-1} \mathrm{~h}^{-1}$ mês $^{-1}$.

Para os meses de abril e maio, as áreas de ocorrência crítica da erosividade concentrou-se na porção centro-norte da bacia, variado entre 352 e $951 \mathrm{MJ} \mathrm{mm} \mathrm{ha}^{-1} \mathrm{~h}^{-1}$ mês $^{-1}$ em abril e entre 228 e $343 \mathrm{MJ} \mathrm{mm} \mathrm{ha}^{-1} \mathrm{~h}^{-1}$ mês $^{-1}$ em maio. Os valores médios correspondentes ao período de junho, julho e agosto não ultrapassaram 234 MJ mm ha ${ }^{-1} \mathrm{~h}^{-1}$ mês $^{-1}$, com os maiores valores na porção leste da bacia. Para os meses de setembro e outubro, a porção leste da bacia, onde os valores são mais elevados, a variação da erosividade ficou entre 231 e $285 \mathrm{MJ} \mathrm{mm} \mathrm{ha-1} \mathrm{h-}$ ${ }^{1}$ mês $^{-1}$ em setembro e entre 415 e $723 \mathrm{MJ}$ mm $h^{-1} h^{-1}$ mês $^{-1}$ em outubro. Em novembro, a porção sudeste da bacia apresentou os valores mais elevados de erosividade, que variam entre 1.157 e 1351 MJ mm ha-1 h $^{-1}$ mês $^{-1}$. No Mês de dezembro, os valores variaram entre $1.964 \mathrm{e}$ 2.170 MJ mm ha-1 $\mathrm{h}^{-1}$ mês $^{-1}$, com o nordeste da bacia apresentando os valores mais críticos.

Considerando a espacialização da erosividade anual, a região sudeste da bacia apresentou os menores valores de erosividade, variando entre 8.332 e $9.253 \mathrm{MJ} \mathrm{mm} \mathrm{ha}^{-1} \mathrm{~h}^{-1}$ ano $^{-1}$. Os maiores valores de erosividade ocorreram em uma pequena porção da região norte e noroeste com variação entre 10.519 e 14.403 MJ mm ha-1 $\mathrm{h}^{-1}$ ano-1 $^{-1}$ e grande porção norte da bacia do rio Manuel Alves da Natividade com valores entre 10.057 e 10.519 (Figura 6).

É importante destacar que a erosividade está intrinsicamente ligada à intensidade das chuvas, portanto, na medida em que a relação intensidade-duração-frequência da chuva aumenta, maior será o potencial erosivo da precipitação pluvial (Fator R). Amanambu et al. (2019), em estudos de variabilidade espacial da erosividade das chuvas na bacia do Rio Níger, África Ocidental, encontraram valores de erosividade anual entre 715 e $17.824 \mathrm{MJ}$ mm $\mathrm{ha}^{-1} \mathrm{~h}^{-1}$ ano $^{-1}$. Embora não seja uma regra geral para todos os casos, os autores afirmam que o aumento na quantidade anual de chuvas levou ao aumento da erosividade e vice-versa. Silva Neto (2016), em estudos sobre as chuvas intensas no Estado do Tocantins, determinou a intensidade da chuva de 30 minutos para um tempo de retorno de 10 anos entre 101 e 108 $\mathrm{mm} \mathrm{h} \mathrm{h}^{-1}$, para a região sudeste do estado do Tocantins, onde se localiza a bacia hidrográfica em questão, o que justifica os elevados valores de erosividade da precipitação pluvial na bacia do Rio Manuel Alves da Natividade. 
Figura 6. Distribuição espacial da erosividade das chuvas na bacia do Rio Manuel Alves da Natividade

(MJ mm ha-1 $\mathrm{h}^{-1}$ ano $^{-1}$ ) para os meses de Janeiro (A), Fevereiro (B), Março (C), Abril (D), Maio (E),

Junho-Julho-Agosto (F), Setembro (G), Outubro (H) Novembro (I), Dezembro (J), erosividade anual (L) e classificação da erosividade segundo Foster et al. (1981) (M)
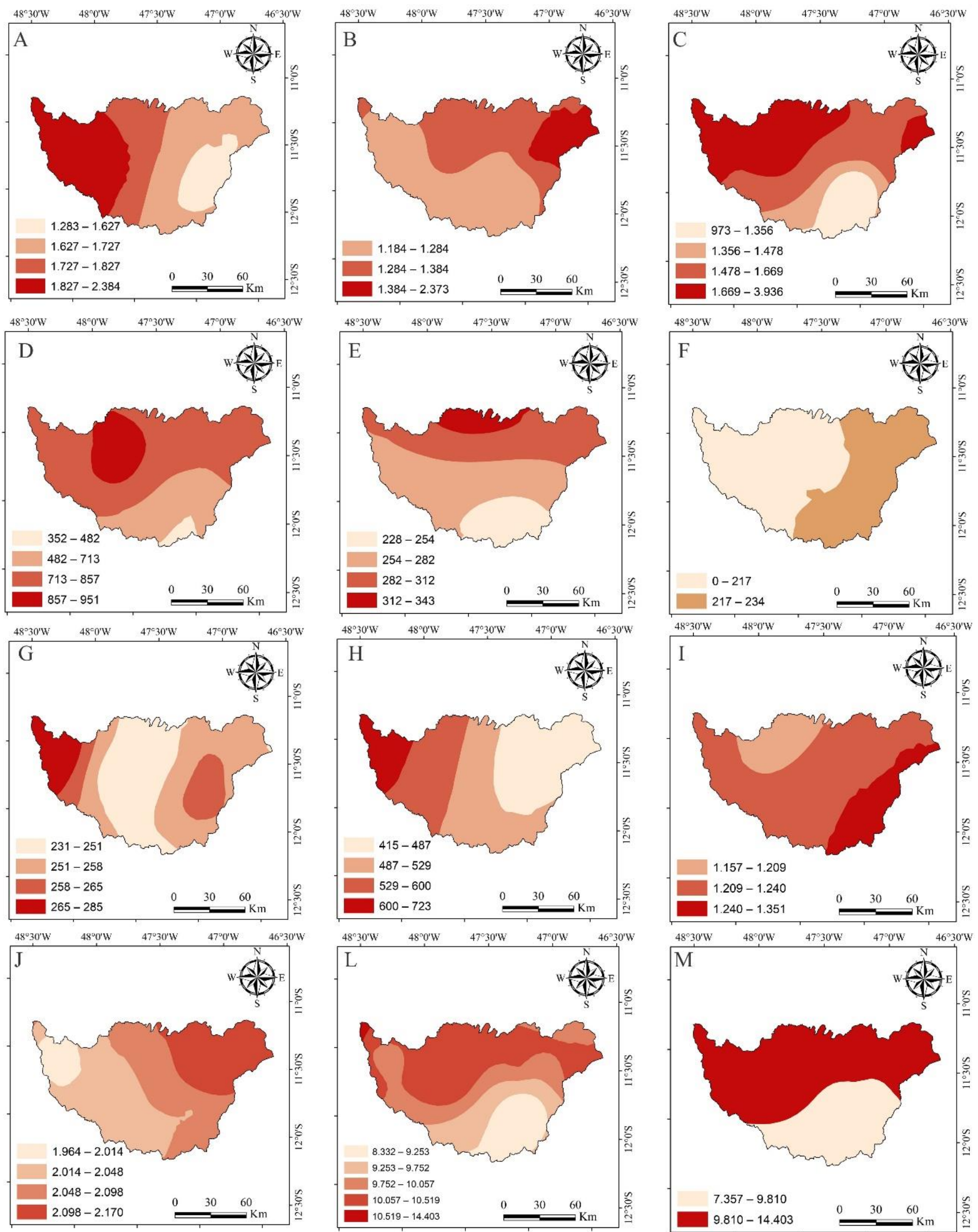

Fonte: Elaborado pelo autor, 2018. 
Deve-se enfatizar a necessidade de adoção de medidas concretas para mitigação dos processos erosivos decorrentes da precipitação pluvial, como o cercamento de áreas críticas para evitar o fluxo de animais, conservação da vegetação nativa, reflorestamento de áreas com maior declividade e a introdução de curvas de nível objetivando a redução do escoamento superficial. Pio de Santana et al. (2007) afirma que a adoção de um sistema de manejo considerando as limitações do terreno, mesmo que seja em áreas fortemente erosivas, a erosividade das chuvas pode ser minimizada e que as respostas interativas entre clima, vegetação, solo e formas de uso e ocupação precisam ser adequadamente quantificadas e monitoradas.

Cabe destacar, que os valores de erosividade foram determinados por meio de uma equação pré-ajustada baseando-se na distribuição geográfica da precipitação anual para regiões homogêneas do território brasileiro, em que foi aplicada a equação proposta Silva et al. (1997), validade por Viola et al. (2014), sendo de fundamental importância a realização de estudos futuros que visem determinar a erosividade das chuvas na bacia do rio Manuel Alves da Natividade por meio do ajuste de equações de erosividade para as chuvas na própria área da bacia, com intuito de averiguar a possibilidade de superestimação e subestimação dos valores encontrados.

Outro aspecto importante se refere às técnicas geoestatística que segundo Mello et al. (2007), estão sendo amplamente aplicadas, mostrando melhor eficácia que as demais. Isto ocorre, principalmente, pelo controle de parcela do erro aleatório produzido pela influência espacial mútua entre as amostras, conhecida como dependência espacial, algo que a estatística clássica não considera.

\section{CONSIDERAÇÕES FINAIS}

A bacia do rio Manuel Alves da Natividade apresenta severo risco natural à erosão hídrica, principalmente nas regiões noroeste, norte e central.

A erosividade das chuvas no Estado do Tocantins, tanto na escala de tempo mensal quanto anual, apresenta estrutura de continuidade espacial entre moderada e forte, com alcance entre 106 e $453 \mathrm{~km}$.

A espacialização da erosividade na bacia em escala mensal e anual apresentou áreas e períodos críticos em relação ao potencial erosivo das chuvas, constituindo informações para o planejamento de uso e manejo sustentável do solo bem como para a implementação de ações para a conservação do solo e da água para a bacia do rio Manuel Alves da Natividade, como cercamento da área, conservação da mata nativa, reflorestamento, cultivo em curva de nível, terraceamento, captação de águas e estruturas de estabilização.

As técnicas geoestatísticas apresentam melhor desempenho que a estatística clássica devido ao controle de parcela do erro aleatório produzido pela influência espacial mútua entre as amostras, conhecida como dependência espacial. Entretanto, a utilização de um número reduzido de estações na área da bacia e seu entorno pode constituir uma limitação dessas técnicas por dificultar a análise de 
dependência espacial.

\section{AGRADECIMENTOS}

Ao Instituto Federal de Educação, Ciência e Tecnologia do Tocantins, pela concessão de bolsa de pesquisa aplicada em Arranjos Produtivos Locais (APL), por meio do Programa de Apoio à Pesquisa (PAP), por meio do Edital 24/2016. Ao professor Marcelo R. Viola, pelos ensinamentos que direcionaram esta pesquisa.

\section{REFERÊNCIAS}

AMANAMBU, A. C.; LI, L.; EGBINOLA, C. N.; OBAREIN, O. A.; MUPENZI, C.; CHEN, D. Spatio-temporal variation in rainfall-runoff erosivity due to climate change in the Lower Niger Basin, West Africa. Catena, v. 172, p. 324-334, 2019. https://doi.org/10.1016/j.catena.2018.09.003

ANA. Agência Nacional das Águas. Hidroweb. Sistema de informações hidrológicas. Disponível em: <http://hidroweb.ana.gov.br>. Acesso em: 10 de maio de 2017.

BERTONI, J.; LOMBARDI NETO, F. Conservação do solo. São Paulo: Ícone, 1999.

CAMBARDELLA, C.; MOORMAN, T.; PARKIN, T.; KARLEN, D.; NOVAK, J.; TURCO, R.; KONOPKA, A. Field-scale variability of soil properties in central Iowa soils. Soil science society of America journal, v. 58, n. 5, p. 15011511 , 1994. https://doi.org/10.2136/sssaj1994.0361599500 5800050033x

CARVALHO, N. D. O. Hidrossedimentologia prática. Rio de Janeiro: Interciência, 2008.

CASSOL, E. A.; ELTZ, F. L. F.; MARTINS, D.; LEMOS, A. D.; LIMA, V. D.; BUENO, A. C. Erosividade, padrões hidrológicos, período de retorno e probabilidade de ocorrência das chuvas em São Borja, RS. Revista Brasileira de Ciência do Solo, v. 32, n. 3, p. 1239-1251, 2008. 06832008000300032

https://doi.org/10.1590/S0100-

FOSTER, G.; MCCOOL, D.; RENARD, K.; MOLDENHAUER, W. Conversion of the universal soil loss equation to SI metric units. Journal of Soil and Water Conservation, v. 36, n. 6, p. 355-359, 1981.

HAAS, J.; SCHACK-KIRCHNER, H.; LANG, F. Adjustment of a weather generator to represent actual rain erosivity in the northern Black Forest-Germany. Catena, v. 163, p. 4253 , 2018. https://doi.org/10.1016/j.catena.2017.12.006

HICKMANN, C. et al. Erosividade das chuvas em Uruguaiana, RS, determinada pelo índice EI30, com base no período de 1963 a 1991.

Revista brasileira de ciencia do solo. Campinas, v. 32, n. 2 p. 825-831, 2008. https://doi.org/10.1590/S0100 06832008000200036

INPE, Instituto Nacional de Pesquisas Espaciais. Catálogo de imagens de satélite. 2016. Disponível em: <http://www3.inpe.br/unidades/cep/atividades cep/educasere/tutorial/blibliografia.pdf>. Acesso em: 16 de agosto de 2017.

LEWIS, C. D. Demand Forecasting and Inventory Control: a computer aided learning approach. Woodhead Publishing Ltd, 1997.

LIEW, M. W.; VEITH, T. L.; BOSCH, D. D.; ARNOLD, J. G. Suitability of SWAT for the conservation effects assessment project: Comparison on USDA agricultural research service watersheds. Journal of Hydrologic Engineering, v. 12, n. 2, p. 173-189, 2007. https://doi.org/10.1061/(ASCE) 10840699(2007)12:2(173)

LOMBARDI NETO, F.; MOLDENHAUER, W. Erosividade da chuva: sua distribuição e relação com perdas de solo em Campinas, SP. Bragantia, v. 51, n. 2, p. 189-196, 1992. https://doi.org/10.1590/S000687051992000200009

MELLO, C. R.; SÁ, M. A. C.; CURI, N.; MELLO, J. M.; VIOLA, M. R.; DA SILVA, A. M. Erosividade mensal e anual da chuva no Estado de Minas Gerais. Pesquisa Agropecuária Brasileira, v. 42, n. 4, p. 537545, 2007. https://doi.org/10.1590/S0100204X2007000400012

MORAIS, L.; SILVA, V. D.; NASCHENVENG, T. D. C.; HARDOIN, P.; ALMEIDA, J. D.; WEBER, O. D. S.; BOEL, E.; DURIGON, V. Índice EI30 e sua relação com o coeficiente de chuva do sudoeste do Mato Grosso. Revista brasileira de ciência do solo, v. 15, n. 3, p. 339-344, 1991.

OLIVEIRA, J. P. B.; CECÍLIO, R. A.; PRUSKI, F. F.; ZANETTI, S. S. Espacialização da erosividade das chuvas no Brasil a partir de séries sintéticas de precipitação. Revista Brasileira de Ciências Agrárias, v. 10, n. 4, 2015. 
https://doi.org/10.5039/agraria.v10i4a4998

SANTANA, N. M. P.; CASTRO, S. S. D.; STONE, L. F.; DA SILVA, S. C. Chuvas, erosividade, erodibilidade, uso do solo e suas relações com focos erosivos lineares na alta bacia do rio Araguaia. Sociedade \& Natureza, v. 19, n. 2, p. 103-121, https://doi.org/10.1590/S198245132007000200007

REBOITA, M. S.; GAN, M. A.; ROCHA, R. P. D.; AMBRIZZI, T. Regimes de precipitacao na America do sul: uma revisão bibliográfica. Revista Brasileira de Meteorologia, v. 25, n. $2, \quad$ p. $185-204, \quad 2010$. https://doi.org/10.1590/S010277862010000200004

SEPLAN. Secretária de Planejamento. Atlas do Tocantins: Subsídios ao Planejamento da Gestão Territorial. Superintendência de Planejamento e Gestão central de Políticas Públicas. Diretoria de Zoneamento EcológicoEconômico - DZE. BORGES, R.S.T.; DIAS, R.R.; SOUSA, P.A.B. (orgs). 6. ed. Palmas: Seplan, p.80, 2012.

SILVA, A. M. D. Rainfall erosivity map for Brazil. Catena, v. 57, n. 3, p. 251-259, 2004. https://doi.org/10.1016/j.catena.2003.11.006.

SILVA, M. D.; SILVA, M. L. N.; CURI, N.; SANTOS, G. R. D.; MARQUES JJGSM, M. M.; LEITE, F. Avaliação e espacialização da erosividade da chuva no Vale do Rio Doce, Região Centro-Leste do Estado de Minas Gerais. Revista Brasileira de Ciência do Solo, Viçosa, v. 34, n. 4, p. 1029-1039, 2010. https://doi.org/10.1590/S010006832010000400003

SILVA, M. L. N.; DE FREITAS, P. L.; BLANCANEAUX, P.; CURI, N. Índices de erosividade das chuvas da região de Goiânia, GO. Pesquisa Agropecuária Brasileira, v. 32, n. 10, p. 977-985, 1997.

SILVA NETO, V. L. Avaliação da erosividade das chuvas na microrregião de Taguatinga-TO. Desafios Rev. Interdisciplinar da Universidade Federal do Tocantins, v. 2, n. $1, \quad$ p. $\quad 14, \quad 2015$. https://doi.org/10.20873/uft.23593652.2015v2n1p149

. Chuvas Intensas no estado do Tocantins. 2016. Dissertação. (Mestrado em Ciências Florestais e Ambientais). Programa de PósGraduação em Ciências Florestais e Ambientais, Universidade Federal do Tocantins - UFT, Gurupi, TO, 2016.

SILVA NETO, V. L.; SILVA, T. B.; SILVA, J. J. D. C. O potencial erosivo das chuvas na Bacia do Rio Manuel Alves. In: $7^{\mathrm{a}}$ Jornada de Iniciação Cientiífica e Extensão. Dianópolis:
Instituto Federal do Tocantins, v. 7, p. 1-8, 2016.

SOUZA, F. H. M. D.VIOLA, M. R.AVANZI, J. C.GIONGO, M.VIEIRA FILHO, M. Thornthwaite's Climate Regionalization for the State of Tocantins, Brazil. Floresta, v. 49, n. $4, \quad$ p. $783-792, \quad 2019$. https://doi.org/10.5380/rf.v49i4.59188

VIOLA, M. R.; AVANZI, J. C.; MELLO, C. R. D.; LIMA, S. D. O.; ALVES, M. V. G. Distribuição e potencial erosivo das chuvas no Estado do Tocantins. Pesquisa Agropecuária Brasileira, v. 49, p. 125-135, 2014. https://doi.org/10.1590/S0100204X2014000200007

VRIELING, A.; STERK, G.; DE JONG, S. M. Satellite-based estimation of rainfall erosivity for Africa. Journal of hydrology, v. 395, n. 34, p. 235-241, 2010. https://doi.org/10.1016/j.jhydrol.2010.10.035

WISCHMEIER, W. H.; SMITH, D. D. Rainfall energy and its relationship to soil loss. Eos, Transactions American Geophysical Union, v. 39, n. 2, p. 285-291, 1958. https://doi.org/10.1029/TR039i002p00285

WISCHMEIER, W. H.; SMITH, D. D. Predicting rainfall erosion losses: a guide to conservation planning. Washington: USDA, 1978. 